Bertan Beylergil*, Alaattin Aktas and Yeliz Pekbey

\title{
Enhancement of flexural performance of wood beams using textile fabrics
}

\begin{abstract}
The aim of this study was to investigate the flexural performance of wood beams (beech - Fagus orientalis Lipsky) reinforced with woven and selected weft knitted glass fabrics, namely, Milano and plain knit. Some physical and mechanical properties of the beech wood and the textile fabrics were determined in accordance with relevant ASTM standards. Twenty-four wood beams which have two different cross sections (I-shaped and square hollow) were manufactured and tested under a threepoint load. They were divided into two groups: Group A specimens were not reinforced to serve as a reference, whereas Group B specimens were reinforced with textile fabrics combined with adhesion. The flexural behavior of the specimens was studied through their load-deflection characteristics. The modes of failure were identified and categorized. The experimental results showed that the load-bearing capacity of reinforced beams increased significantly compared to the beam without reinforcement. This method can be used to repair and strengthen damaged wood beams.
\end{abstract}

Keywords: fabrics/textiles; flexural performance; knitting; wood.

*Corresponding author: Bertan Beylergil, İzmir Institute of Technology, Mechanical Engineering Department, Gülbahçe Campus, 35437 Urla, İzmir, Turkey, Phone: +90 232750 6700, Fax:+90 232750 6701, e-mail: bertanbeylergil@gmail.com Alaattin Aktas: Department of Mechanical Engineering, Faculty of Engineering, Istanbul University, 34320 Avcilar, Istanbul, Turkey Yeliz Pekbey: Department of Mechanical Engineering, Faculty of Engineering, Ege University, 35100 Bornova-Izmir, Turkey

\section{Introduction}

Despite its limited weight density, wood has very unique properties including good resistance under compressive and tension loads. Wood-based elements, glues, joining methods and additional fastener components are some of the products that have become available with the advanced technology. However, their durability is questionable due to some of their characteristics. Starting in the early 1960s, reinforcement with conventional techniques employing both fiber-reinforced plastics (FRP) and non-FRP materials has been studied $[1,2]$ The following review summarizes some of these studies. Mark [3] investigated the effects of bonding aluminum to the compression and tension faces of wood core sections of eight different wood species. Lantos [4] reinforced rectangular laminated wood beams with steel rods. Stern and Kumar [5] studied the effect of steel plate reinforcement for vertically laminated timber beams. Coleman and Hurst [6] reinforced No. 2 southern pine beams with light gauge steel reinforcement. Hoyle [7] proposed inserting thin plates of steel or aluminum both vertically and horizontally between the lamellae of wood. Steel components are susceptible to corrosion and aluminum plates may buckle when thermal loads are applied. They also cause increased dead loads, high transportation and installation costs [8]. Wangaard [9] and Biblis [10] studied the effects of bonding unidirectional FRP to the compression and tension faces of wood cores of various species. Plevris and Triantafillou [11] reported on the effects of reinforcing fir wood with carbon/epoxy FRP. Plevris and Triantafillou [12] also investigated the creep behavior demonstrated by FRP-reinforced wood. Triantafillou and Deskovic [13] studied the effect of pre-stressed carbon/epoxy FRP reinforcement bonded to European beech lumber. Dempsey and Scott [14] studied the effects of mechanically fastening FRP strips on wood members. Anido et al. [15] looked into repair methodology of the wood piles by using pre-fabricated FRP composite shells. Scientists have proven that the use of FRP composites is one of the most promising technologies for repairing, strengthening or retrofitting existing structures to resist higher loads and to rectify damaged flexural structural elements.

Nowadays, textile composites are increasingly being used in advanced structures in aerospace, automobile and marine industries. The application of textile composites in engineering structures has been driven by various attractive aspects such as ease of handling, high adaptability, light weight and high specific stiffness. Textile composites are generally classified into three basic categories according to the textile forming techniques used for composite reinforcement: (i) woven fabrics, (ii) knitted fabrics and (iii) braided fabrics. Compared with the other 
conventional textile fabrics, knitted fabrics possess high productivity and low cost. In addition, knitted fabrics have high extensibility which means good formability to fit in complicated shapes $[16,17]$.

As stated earlier, improving the flexural properties of wood beams by reinforcement has engaged the attention of scientists for many years. Although this is not a novel concept, there is no research related specifically to textile fabrics as reinforcements for wood beams. This study presents the results of experimental investigations on the flexural behavior of wood beams reinforced with knitted fabrics. A total of 24 wood beams with different cross sections, namely, I-shaped and square hollow were manufactured and tested under a three-point load. They were divided into two groups: Group A specimens were not reinforced and served as a reference, whereas Group B specimens were reinforced with woven, Milano and plain fabrics. Some physical and mechanical properties of the wood and the textile fabrics were determined in accordance with relevant ASTM standards. The flexural behavior of the beams was studied through their load-deflection characteristics and the failure modes.

\section{Materials}

\subsection{Wood material}

The oriental beech (Fagus orientalis Lipsky) trees which were obtained from the Mengen District at the Bolu Yaylacik Research Forest, Turkey were used in this study. The study site was located $1475 \mathrm{~m}$ above sea level. Before cutting down the trees, they were carefully inspected to make sure that they were normal and structurally intact. There were no signs or symptoms of insect colonization or fungal infection. The average age of the trees was 110 years. The small and clear specimens were prepared according to ASTM D143-94 [18] and they were placed into a climatization room at a temperature of $20 \pm 2^{\circ} \mathrm{C}$ and a relative humidity of $65 \pm 5 \%$, until the average moisture content of $12 \%$ was reached. Following this step, the specimens were stored in plastic bags to prevent the loss of humidity and subsequently used for tests.

The bending tests were performed using Instron universal testing machine at a constant crosshead speed of $2.54 \mathrm{~mm} / \mathrm{min}$ as recommended by ASTM D198-09 [19]. Ten specimens with the dimensions of $622.3 \mathrm{~mm}(L) \times 38.1 \mathrm{~mm}$ $(b) \times 88.9 \mathrm{~mm}(h)$ were tested. Static bending strength of the specimen [modulus of rupture (MOR)] was calculated from the elementary bending theory using Eq. (1):

$$
\mathrm{MOR}=\frac{3 P_{\mathrm{b}} L}{2 b h^{2}}
$$

where $P_{\mathrm{b}}$ is the failure load $(\mathrm{N})$ in bending, $L$ is the length of span, $b$ is the width of specimen (mm) and $h$ is the thickness of the specimen (mm). The flexural modulus of elasticity (MOE) was calculated by fitting a line to the elastic region of the load-displacement curve and utilizing the following equation:

$$
E=\frac{m}{4 b}\left(\frac{L}{h}\right)^{3}
$$

where $m$ is the slope of elastic region. The compression tests were carried out on the same universal testing machine. The specimens with the dimensions of $25 \mathrm{~mm} \times 20 \mathrm{~mm} \times$ $20 \mathrm{~mm}$ were prepared. The test was conducted at a crosshead speed of $0.6 \mathrm{~mm} / \mathrm{min}$. The ultimate compression strength (UCS) parallel to the grain of the specimen was calculated using Eq. (3):

$$
\mathrm{UCS}=\frac{P_{\mathrm{c}}}{A}
$$

where $P_{c}$ is the failure load $(\mathrm{N})$ in compression and $A$ is the cross-sectional area of the specimen $\left(\mathrm{mm}^{2}\right)$. After testing, the moisture content (MC) was determined using a small piece, $25.4 \mathrm{~mm}$ long, cut from the specimen immediately after the testing from the location close to the failure according to ASTM D4442-92 [20]. Average MC for the test samples were: $12.5 \%$ (minimum $11.0 \%$, maximum $13.0 \%$ ) for bending, and $11.2 \%$ (minimum 10.4\%, maximum 13.2\%) for compression. Each measured property value was converted to $12 \% \mathrm{MC}$ values using the following formula [21]:

$$
P_{2}=P_{1}+\left(\frac{P_{1}-B_{1}}{B_{2}-M_{1}}\right)\left(M_{1}-M_{2}\right)
$$

where $P_{1}$ is the mechanical property value at the initial moisture content and $P_{2}$ is the adjusted mechanical property at $12 \%$ MC. In Eq. (4), $M_{1}$ is the initial moisture content, $M_{2}$ is $12 \%$ and $B_{1}, B_{2}$ are constants (Table 1). The

Coefficients

Property (MPa)

\begin{tabular}{lrr}
\cline { 2 - 3 } & MOR & UCS \\
\hline$B_{1}$ & 16.6 & 9.6 \\
$B_{2}$ & 0.276 & 0.234 \\
\hline
\end{tabular}

Table 1 Coefficients for moisture adjustment of dimension lumber mechanical properties with change in moisture content. 
MOE value was also converted to $12 \%$ MC value by using the following equation [21]:

$$
E_{1}=E_{2}\left(\frac{1.857-0.0237 M_{2}}{1.857-0.0237 M_{1}}\right)
$$

where $E_{1}$ is the value of MOE at initial moisture content and $E_{2}$ is the value of MOE at $12 \% \mathrm{MC}$. In order to calculate the air-dried density $\left(D_{12}\right)$, ten specimens with the dimensions of $30 \mathrm{~mm} \times 20 \mathrm{~mm} \times 20 \mathrm{~mm}$ were prepared. They were weighted for every 6-h interval on an electronic scale with a sensitivity of $0.001 \mathrm{~g}$, and their dimensions were measured. The air-dried density $\left(D_{12}\right)$ was calculated as follows:

$$
D_{12}=\frac{m_{12}}{V_{12}}
$$

where $m_{12}$ and $V_{12}$ are the mass $(\mathrm{g})$ and volume $\left(\mathrm{cm}^{3}\right)$ of the specimens, respectively. In order to determine ovendried density, the same specimens were used. They were dried at $103 \pm 2^{\circ} \mathrm{C}$ until a constant weight was obtained and weighted on an electronic scale with a sensitivity of $0.001 \mathrm{~g}$, and their dimensions were measured. The ovendried density $\left(D_{0}\right)$ was calculated as follows:

$$
D_{0}=\frac{m_{0}}{V_{0}}
$$

where $m_{0}$ and $V_{0}$ is the mass $(\mathrm{g})$ and volume $\left(\mathrm{cm}^{3}\right)$ of the dried specimens, respectively. The determined physical and mechanical properties of beech wood are given in Table 2.

\subsection{Reinforcement materials}

Two types of reinforcement materials: (i) knitted and (ii) woven fabrics were used in this study. Knitted fabrics are manufactured by looping the yarn through itself to make a chain of stitches which are then connected together. This procedure is different from weaving where yarns cross over one another. There are two types of knitted fabric those manufactured by (i) weft knitting and (ii) warp

\begin{tabular}{rrrrr} 
MOR $(\mathrm{MPa})$ & MOE $(\mathrm{MPa})$ & $\mathrm{UCS}(\mathrm{MPa})$ & $D_{12}\left(\mathrm{~g} / \mathrm{cm}^{3}\right)$ & $D_{0}\left(\mathrm{~g} / \mathrm{cm}^{3}\right)$ \\
\hline 76.49 & 11.6 & 63.15 & 0.66 & 0.63 \\
\hline
\end{tabular}

Table 2 Some physical and mechanical properties of beech wood at $12 \% \mathrm{MC}$. knitting. For weft knitting, there is only a single feed of yarn coming into the machine at $90^{\circ}$ to the direction of fabric production and this yarn forms a row of knit loops across the width of the fabric. In warp knitting, there are multiple yarns being fed into the machine in the direction of fabric production, and each yarn forms a line of knit loops in the fabric direction. The knitting directions are also named wale and course [22].

Two different weft knitted fabrics were constructed on a seven-gauge flatbed knitting machine from 130 tex glass yarn with a slight twisting under the same knitting conditions. The fabric configurations were 'plain' and 'Milano'. Their appearance and schematic diagrams are shown in Figure 1. The physical properties of each knitted fabric are summarized in Table 3. The wale and course densities are defined as the number of wales and courses per unit length in the course and wale directions, respectively. Area density refers to the mass of fabric per unit area. The last type of reinforcement textile fabric was the plain weave (woven) fabric with a weight of $320 \mathrm{~g} / \mathrm{m}^{2}$. The fiber volume fraction was $50 \%$. The mechanical properties of the textile fabrics were determined in accordance with ASTM standards [23-25] and given in Table 4.
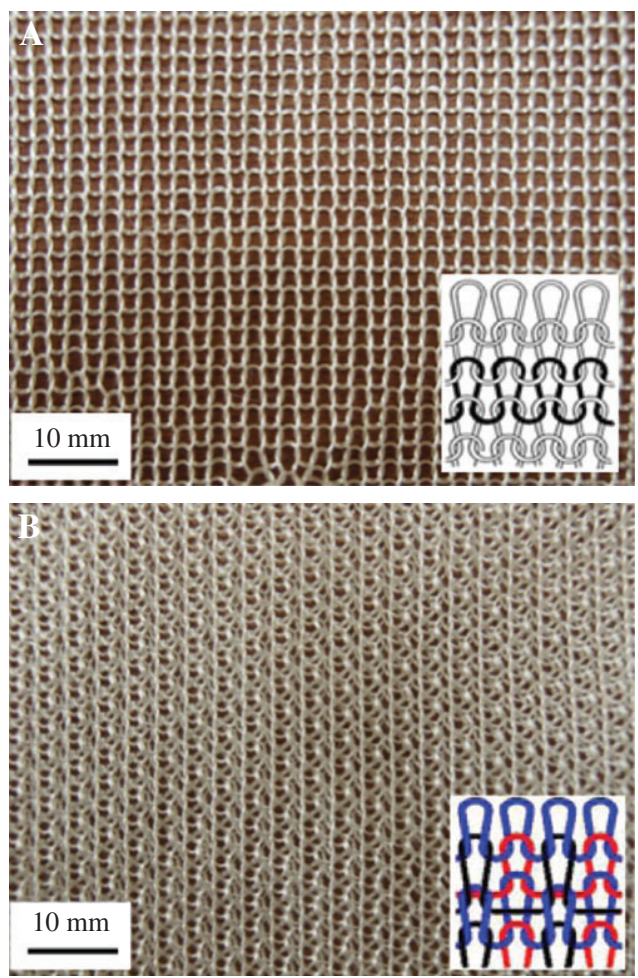

Figure 1 Photograph and schematic diagram of weft knitted fabrics. (A) Plain knit, (B) Milano. 


\begin{tabular}{lrrrrr}
$\begin{array}{l}\text { Fabric } \\
\text { type }\end{array}$ & $\begin{array}{r}\text { Thickness } \\
(\mathrm{mm})\end{array}$ & $\begin{array}{r}\text { Loop } \\
\text { length } \\
(\mathrm{mm})\end{array}$ & $\begin{array}{r}\text { Area } \\
\text { density } \\
\left(\mathrm{g} / \mathrm{m}^{2}\right)\end{array}$ & $\begin{array}{r}\text { Course } \\
\text { density } \\
\text { (course/cm) }\end{array}$ & $\begin{array}{r}\text { Wale } \\
\text { density } \\
\text { (wale/cm) }\end{array}$ \\
\hline Plain & 0.1 & $5.0-5.4$ & 328 & 5 & 3.5 \\
Milano & 0.2 & $5.2-5.9$ & 385 & 5 & 3.5 \\
\hline
\end{tabular}

Table 3 Some physical properties of knitted fabrics.

\subsection{Adhesives}

Two different types of adhesives were used in the preparation of test specimens: (i) polyvinyl acetate (PVAc) (Kleiberit 303) and (ii) two-component epoxy adhesive. PVAc was supplied from a local manufacturer and used as delivered. According to the manufacturer data, the specific density of the PVAc adhesive is $1.05 \mathrm{~g} / \mathrm{cm}^{3}$, its viscosity is $12-18 \mathrm{PaS}\left(\right.$ at $20^{\circ} \mathrm{C}$ ) and its assembly time is $8 \pm 1 \mathrm{~min}$. The second adhesive was prepared by the following steps: The polyester resin was put into a container and cobalt (II) naphthenate promoters added to this container in the ratio of $0.4 \%$ by weight in order to improve cure rate of unsaturated polyester resin. After adding the promoter, the resin was left undisturbed approximately 30 min before adding the activator. Then, methyl ethyl ketone peroxide activator, which initiates the polymerization of polyester resin, was added to the polyester/cobalt mixture by using a syringe in the ratio of $2 \%$ by weight. The prepared adhesive has a fast cure time at room temperature. A small amount of adhesive was prepared for each application.

\section{Specimen preparation and testing procedure}

The felled trees were cut into lumber with the size of $850 \mathrm{~mm}(L) \times 120 \mathrm{~mm}(b) \times 30(h) \mathrm{mm}$, then the lumber was dried in an oven until its humidity level reached $12 \%$. The thickness $(h$ ) of the lumber was reduced to $20 \mathrm{~mm}$ by using a planing machine and was cut to $800 \mathrm{~mm}$ in length and

\begin{tabular}{lrrrr} 
Fabric type & $E_{1}(\mathrm{MPa})$ & $E_{2}(\mathrm{MPa})$ & $G_{12}(\mathrm{MPa})$ & $\mathbf{v}_{12}(-)$ \\
\hline Woven & 30.76 & 25.17 & 3.32 & 0.21 \\
Plain & 7.91 & 4.22 & 1.60 & 0.17 \\
Milano & 12.47 & 8.17 & 6.81 & 0.18 \\
\hline
\end{tabular}

Table 4 Mechanical properties of knitted glass-epoxy composite ${ }^{1,2}$. ${ }^{1}$ fibers direction; ${ }^{2}$ transverse direction.
$100 \mathrm{~mm}$ in width with a circular saw. Three identical wood parts were prepared by this way and they were sanded lightly with 100-grit sandpaper and finished with 200grit sandpaper. The collected sawdust was blown away by using an air compressor and the surfaces were cleaned before applying PVAc adhesive. In order to manufacture I-shaped beams, these parts were bonded together by the adhesive which was held in a container and applied to the bonding surfaces with a brush. To align the wood parts correctly, several markings were placed. The specimens were then left undisturbed for $24 \mathrm{~h}$ in a special metal mold until the adhesive is fully cured under laboratory conditions. In order to manufacture square hollow beams, four wood parts were prepared - two of them with the dimensions of $800 \mathrm{~mm} \times 60 \mathrm{~mm} \times 20 \mathrm{~mm}$ and the others with the dimensions of $800 \mathrm{~mm} \times 100 \mathrm{~mm} \times 20 \mathrm{~mm}$ and bonded together by the adhesive. The specimens were left to cure over the next $24 \mathrm{~h}$ under laboratory conditions. The dimensions of I-shaped and square hollow beams are shown in Figure 2.

A total of 24 beams were prepared. Group A comprised six of these specimens (three specimens for each cross section) which were not reinforced and tested immediately as a reference. Group B comprised the remaining 18 beams (nine specimens for each cross section). The textile fabrics (woven, plain and Milano)
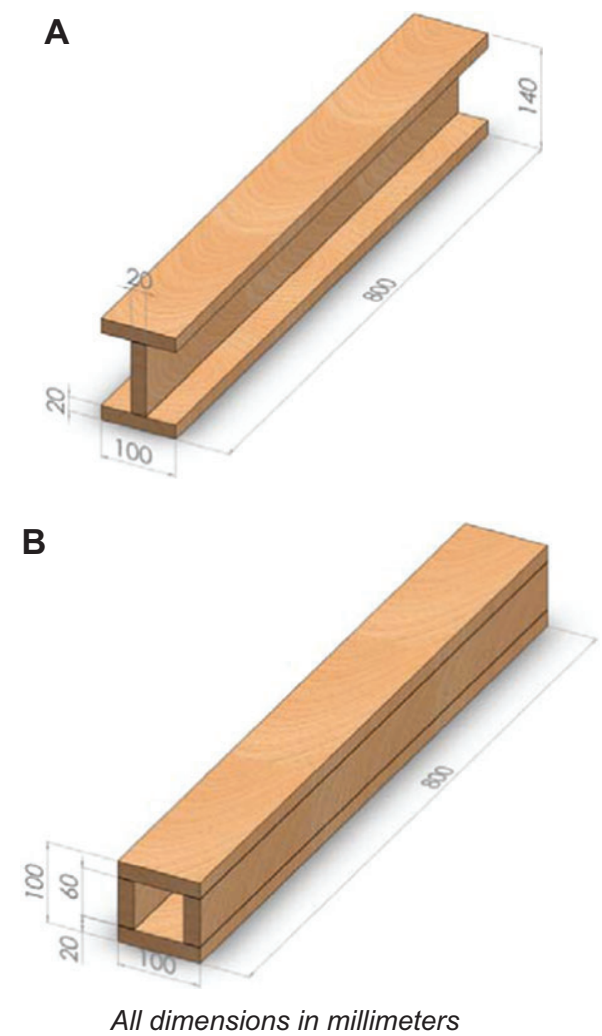

Figure 2 Dimensions of (A) I-shaped and (B) square hollow beams. 
were wrapped around these beams externally after the two-component adhesive was applied to the surfaces to be bonded (three specimens for each reinforcement). In order to achieve the fabric bonding to the interior surfaces of the beams consistently, special wooden molds were used. The wrapping procedure was repeated several times until the woven reinforcement thickness reached $1 \mathrm{~mm}$ and then the beams were cured for $24 \mathrm{~h}$ under laboratory conditions. The same procedure was followed for plain and Milano reinforcement as well. The fabrics were carefully laid onto the beam surface and they were not stretched during this step. The photographs of Group A and Group B specimens are shown in Figure 3.

Three-point bending tests were carried out by using UTEST flexural machine (UTC4520) with a capacity of 100 $\mathrm{kN}$. The load was gradually applied at mid-span with a speed of $2.5 \mathrm{~mm} / \mathrm{min}$. During testing of the specimens, the temperature in the laboratory was stable at $20 \pm 3^{\circ} \mathrm{C}$ while the relativity humidity remained within a range between $55 \%$ and $60 \%$. The experiments were repeated three times with the test setup shown in Figure 4. This was done for both unreinforced and reinforced beams. Figure 5 shows a photograph of Group B specimen under test. The load and displacement curves for both unreinforced and reinforced beams were recorded until complete failure. After failure, photographs were taken and the specimens were inspected to determine the mode of failure.
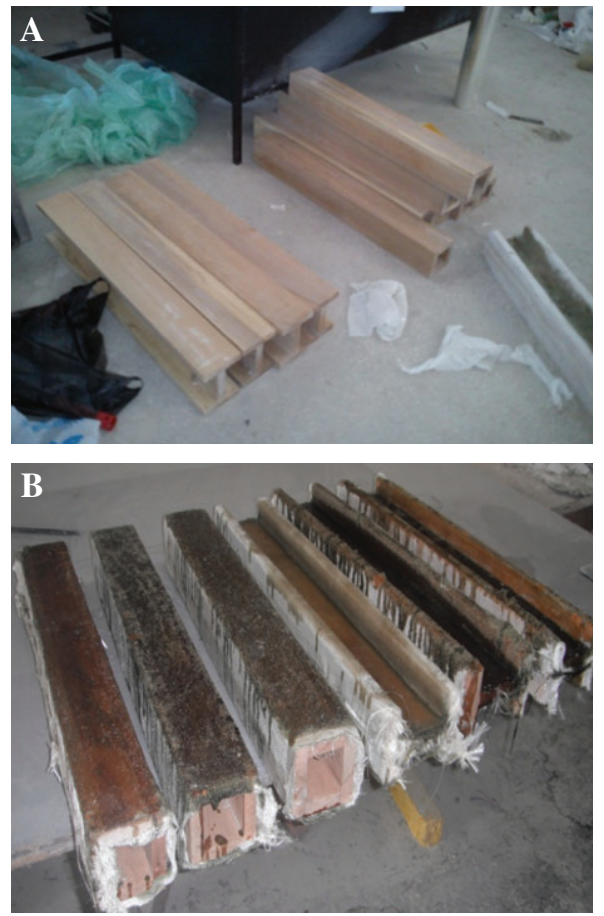

Figure 3 Photographs of (A) Group A and (B) Group B specimens.

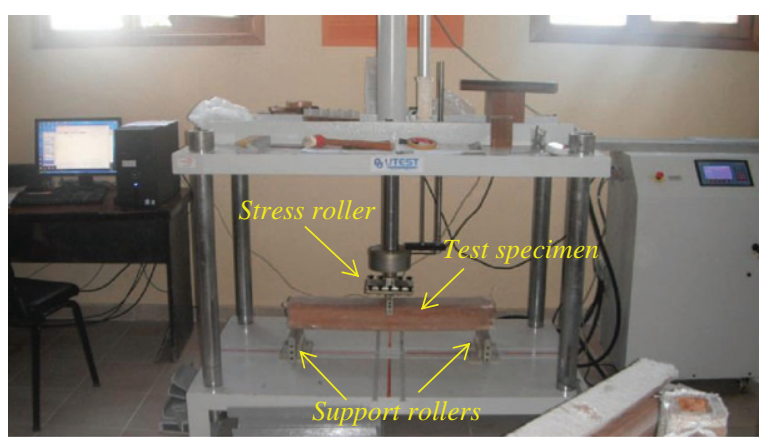

Figure 4 Experimental test setup.

\section{Results and discussion}

Figures 6 and 7 show the load-displacement curves of the I-shaped and square hollow beam specimens, respectively. As seen in the figures, the curves were almost linear (point C) until the initial cracks occurred, and then the stiffness began to decrease gradually. At this stage, first noises in the form of snapping sounds from the beam started to come. Due to small cracking during testing, some slight drops in load were observed in the load-displacement curves (between points $\mathrm{C}$ and D). After some displacement, collapse of the beams occurred (point D). It was noticed that the bending test on all wood beams highlighted a notable increase, when compared to the unreinforced beams in terms of the ultimate load. Additionally, the reinforced beams with textile fabrics also indicated enhanced flexural stiffness so that the reinforced beams experienced lower displacement than the unreinforced beam at high load level beyond the linear region. This is very desirable in the aspect of serviceability limit states. It can be also seen that the displacement value at which the complete failure occurred was almost the same for all specimens because the adhesive bonds failed after reaching this

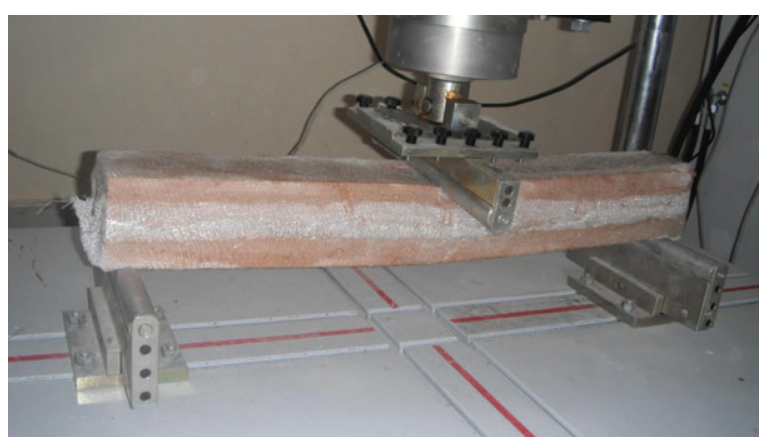

Figure 5 Photograph of Group B specimen under test. 


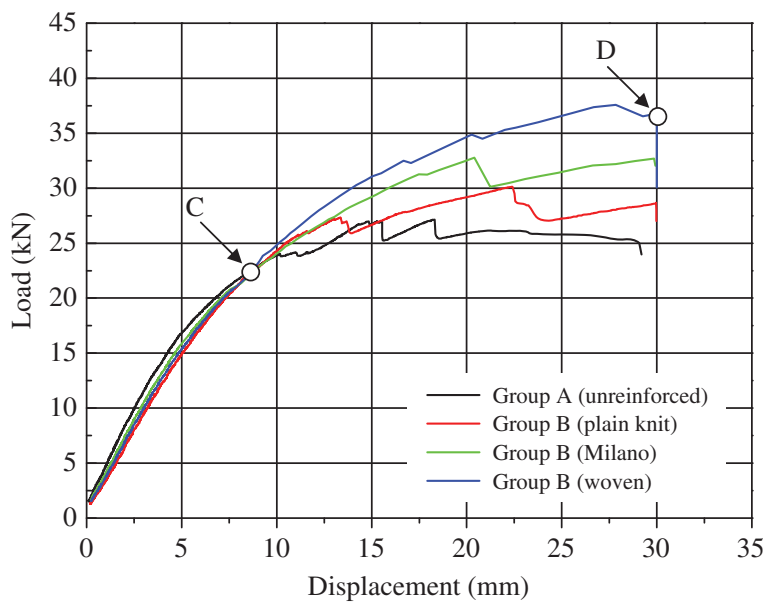

Figure 6 Load-displacement curves of I-shaped beams.

value. Figure $8 \mathrm{~A}$ shows total beam failure resulting from flange failure for the Group A specimen with I-shaped cross section. The red arrows indicate the locations of the failure observed in the beam. As visualized, the bottom and top flange of the beam failed while the web remained stable. This failure occurred because of two reasons: (i) relatively higher moment of inertia of the web and (ii) the wood is much stronger along the direction of the grain. Figure $8 \mathrm{~B}$ shows the failure in the Group A specimen with square hollow cross section. The failure began on the top side shortly after the elastic limit reached and extended downward. Also visualized is the penetration of the stress roller into the beam through its upper side and the shear failure occurring on the lower side. The trace of the stress roller was deeper near the lateral edges of the beam because these edges were more resistant to bending. We observed a similar

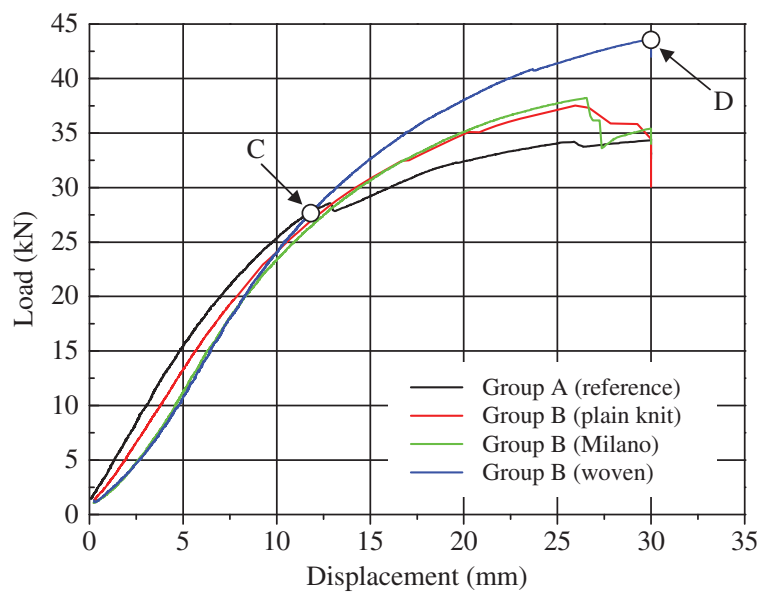

Figure 7 Load-displacement curves of square hollow beams.
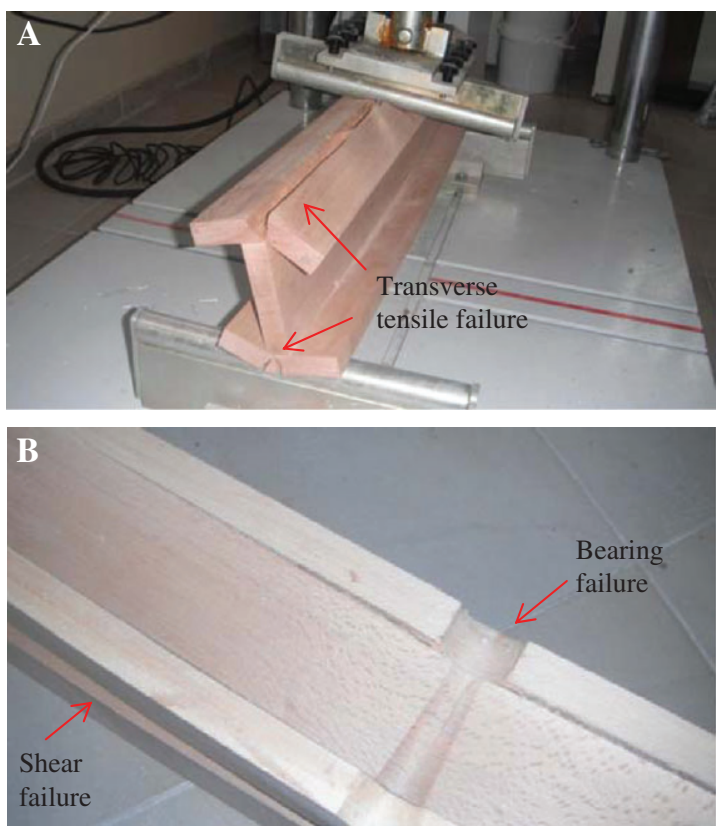

Figure 8 Photographs of failed Group A specimens. (A) I-shaped and (B) square hollow beams.

failure mode for reinforced beams. Figure 9 shows observed failure in the Group B specimens with square hollow cross section. Compared to Group A specimens, the trace of the stress roller was less noticeable and the roller provided more uniform trace on top of the beam because the load was more uniformly distributed over the beam due to the fabric reinforcement (Figure 9A).
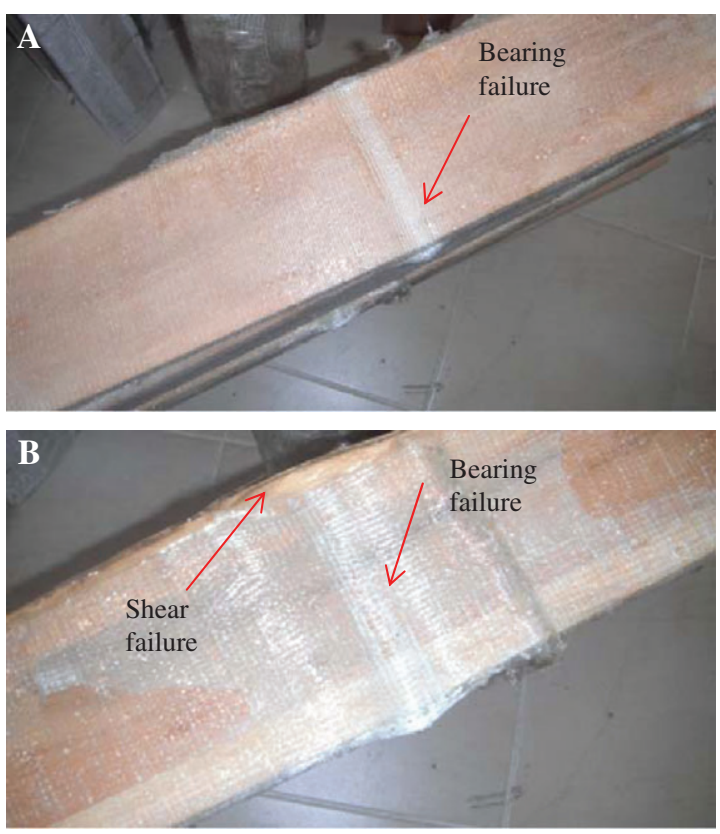

Figure 9 Photographs of failed Group B specimens. (A) I-shaped and (B) square hollow beams. 


\begin{tabular}{lllrrr} 
Specimen & $\begin{array}{l}\text { Cross- } \\
\text { sectional area }\end{array}$ & $\begin{array}{l}\text { Type of } \\
\text { reinforcing }\end{array}$ & $\begin{array}{r}\text { Average ultimate } \\
\text { load (kN) })^{\mathbf{1}}\end{array}$ & $\begin{array}{r}\text { Average failure } \\
\text { displacement (mm) })^{\mathbf{1}}\end{array}$ & $\begin{array}{r}\text { Increased percentage } \\
\text { of average failure load (\%) }\end{array}$ \\
\hline Group A & I-shaped & No & $24.93(2.98 \%)$ & $28.11(11.12 \%)$ & - \\
Group B & & Woven & $38.10(6.57 \%)$ & $29.88(9.19 \%)$ & 14.83 \\
Group B & & Plain knit & $28.55(1.56 \%)$ & $27.55(13.25 \%)$ & 19.94 \\
Group B & & Milano & $29.90(3.28 \%)$ & $28.93(10.66 \%)$ & - \\
Group A & Square hollow & No & $32.20(6.77 \%)$ & $29.14(10.51 \%)$ & 40.15 \\
Group B & & Woven & $45.13(4.55 \%)$ & $30.81(9.35 \%)$ & 10.60 \\
Group B & & Plain knit & $35.61(2.01 \%)$ & $29.34(7.80 \%)$ & 15.37 \\
Group B & & Milano & $37.15(2.69 \%)$ & $28.99(6.27 \%)$ & \\
\hline
\end{tabular}

Table 5 Results summary of bending tests.

${ }^{1}$ The values in parentheses () represent the coefficient of variation.

It was also noted that the fabric failed by tearing along the side edges of the beam and a noticeable shrinking of fabric was also observed over the beam (Figure 9B).

The experimental results of the specimens are shown in Table 5. For I-shaped cross section beams, the average ultimate load of the unreinforced beams was at $24.93 \mathrm{kN}$. Woven fabric reinforcement caused an enhancement of ultimate load from 24.93 to $38.10 \mathrm{kN}$ which represents an increase of 52.83\%. By reinforcing the specimens with plain knit and Milano fabric, ultimate load reached the value of $28.55 \mathrm{kN}$ and $29.90 \mathrm{kN}$, respectively. The total increased percentages of the ultimate load for plain knit and Milano reinforcement were $14.52 \%$ and $19.94 \%$, respectively. There was a slight difference in the ultimate loads of reinforced beams with plain knit and Milano fabric. As expected, the higher percentage of the ultimate load of woven reinforced beams was more significant compared to the others because of the higher elasticity. The average ultimate load of the unreinforced square hollow beams was $32.20 \mathrm{kN}$ which is higher than the average ultimate load of unreinforced I-shaped beams. The increased percentages of the average ultimate load for the square hollow beams reinforced with woven, plain knit and Milano fabrics were $40.15 \%, 10.60 \%$ and $15.37 \%$, respectively. Although the experimental data show a little scatter, a clear increase was noticed in ultimate failure load for the reinforced beams.

\section{Conclusions}

This study presented the results of a series of three-point bending tests that were conducted to failure on wood beams either unreinforced or reinforced with textile fabrics (woven, plain knit and Milano) to determine their flexural performance. The following conclusions can be drawn from the test results:

1. The bending test on all wood beams highlighted a notable increase, when compared to the unreinforced beams in terms of the ultimate load.

2. The reinforced beams with textile fabrics also indicated enhanced flexural stiffness so that the reinforced beams experienced lower deflection than the unreinforced beam at the same load level.

3. The increased percentages of the average ultimate load for the I-shaped beams reinforced with woven, plain knit and Milano fabrics were 52.83\%, 14.52\% and $19.94 \%$, respectively.

4. The increased percentages of the average ultimate load for the square hollow beams reinforced with woven, plain knit and Milano fabrics were $40.15 \%$, $10.60 \%$ and $15.37 \%$, respectively.

5. This method can be used to repair and strengthen damaged wood beams.

Received September 4, 2012; accepted November 23, 2012; previously published online December 21, 2012

\section{References}

[1] Borri A, Corrodi M, Grazini A. Composites Part B 2005, 36, 143-153.

[2] Yerlikaya NC, Aktas A. Mater. Des. 2012, 37, 393-401.

[3] Mark R. For. Prod. J. 1961, 11, 477-484.

[4] Lantos G. Wood Sci. 1970, 2, 136-143.

[5] Stern EG, Kumar VK. For. Prod. J. 1973, 23, 40-47.

[6] Coleman GE, Hurst HT. For. Prod. J. 1974, 24, 45-53.
[7] Hoyle RJ. For. Prod. J. 1975, 25, 17-23.

[8] Kim YJ, Harries KA. Eng. Struct. 2010, 32, 3225-3234.

[9] Wangaard F. For. Prod. J. 1964, 14, 256-260.

[10] Biblis EJ. For. Prod. J. 1965, 15, 81-88.

[11] Plevris N, Triantafillou TC. J. Mater. Civil Eng. 1992, 4, 300-317.

[12] Plevris N, Triantafillou TC. J. Struct. Eng. 1995, 121, 174-186. 
[13] Triantafillou TC, Deskovic N. J. Struct. Eng. 1992, 118, 1270-1284.

[14] Dempsey DD, Scott DW. J. Compos. Constr. 2006, 10, 392-398.

[15] Anido RL, Michael AP, Sandford TC, Goodell B. J. Perform. Constr. Facil. 2005, 19, 78-87.

[16] Asi O, Aktas A, Tercan M, Yuksekkaya ME. J. Reinf. Plast. Compos. 2010, 29, 86-93.

[17] Tercan M, Asi O, Aktas A. Compos. Struct. 2007, 78, 392-396.

[18] American Society for Testing and Materials. Standard Methods of Testing Small Clear Specimens of Timber, ASTM D 143-94, ASTM International: West Conshohocken, PA, 1995, pp. 1-31.

[19] American Society for Testing and Materials. Standard Methods of Static Test of Lumber in Structural Size, ASTM D 198-09, ASTM International: West Conshohocken, PA, 2009, pp. 1-26.

[20] American Society for Testing and Materials. Standard Test Methods for Direct Moisture Content Measurement of Wood and Wood-Based Materials, ASTM D 4442-92, ASTM International: West Conshohocken, PA, 1997, pp. 1-5.
[21] American Society for Testing and Materials. Standard Practice for Establishing Allowable Properties for Visually Graded Dimension Lumber from In-Grade Test of Full-Size Specimens, ASTM D 1990-07, ASTM International: West Conshohocken, PA, 2007, pp. 1-29.

[22] Tong L, Mouritz AP, Bannister M. 3D Fibre Reinforced Polymer Composites, Elsevier Science: Oxford, 2002, p. 32.

[23] American Society for Testing and Materials. Standard Test Method for Tensile Properties of Fiber-Resin Composites, ASTM D 3039-76, ASTM International: West Conshohocken, PA, 1989, pp. 118-122.

[24] American Society for Testing and Materials. Standard Test Method for Compressive Properties of Unidirection or Cross-Ply Fiber-Resin Composites, ASTM D 3410-87, ASTM International: West Conshohocken, PA, 1987, pp. 132-141.

[25] American Society for Testing and Materials. Standard Test Method for In-Plane Shear Strength of Reinforced Plastics, ASTM D 3846-94, ASTM International: West Conshohocken, PA, 1994, pp.1-3. 